\title{
UKPDS 50: Risk factors for incidence and progression of retinopathy in Type II diabetes over 6 years from diagnosis
}

\author{
I. M. Stratton ${ }^{1}$, E. M. Kohner ${ }^{2}$, S. J. Aldington ${ }^{3}$, R. C. Turner ${ }^{*}$, R. R.Holman ${ }^{1}$, S. E. Manley ${ }^{1}$, D. R. Matthews ${ }^{4}$ for the $^{2}$ \\ UKPDS Group
}

${ }^{1}$ Diabetes Trials Unit, Oxford Centre for Diabetes, Endocrinology \& Metabolism, University of Oxford, UK

${ }^{2}$ Department of Medicine, St. Thomas' Hospital, London, UK

${ }^{3}$ Retinopathy Grading Centre, Imperial College School of Medicine, London, UK

${ }^{4}$ Oxford Centre for Diabetes, Endocrinology \& Metabolism, Radcliffe Infirmary, Oxford, UK

\section{Abstract}

Aims/hypothesis. To determine risk factors related to the incidence and progression of diabetic retinopathy over 6 years from diagnosis of Type II (non-insulindependent) diabetes mellitus.

Methods. This report describes 1919 patients from within the United Kingdom Prospective Diabetes Study (UKPDS), with retinal photographs taken at diagnosis and 6 years later and with complete data available. Photographs were centrally graded for lesions of diabetic retinopathy using the modified Early Treatment of Diabetic Retinopathy Study Final scale. Risk factors were assessed after 3 months diet from the time of diagnosis of diabetes. Patients were seen every 3 months in a hospital setting. Biochemical measurements were done by a central laboratory. End points of vitreous haemorrhage and photocagulation were confirmed by independent adjudication of systematically collected clinical data. The main outcome measures were incidence and progression of retinopathy defined as a two-step Early Treatment of Diabetic Retinopathy Study (ETDRS) final scale change.
Results. Of the 1919 patients, 1216 (63\%) had no retinopathy at diagnosis. By 6 years, $22 \%$ of these had developed retinopathy, that is microaneurysms in both eyes or worse. In the 703 (37\%) patients with retinopathy at diagnosis, $29 \%$ progressed by two scale steps or more. Development of retinopathy (incidence) was strongly associated with baseline glycaemia, glycaemic exposure over 6 years, higher blood pressure and with not smoking. In those who already had retinopathy, progression was associated with older age, male sex, hyperglycaemia (as evidenced by a higher $\mathrm{HbA}_{1 \mathrm{c}}$ ) and with not smoking.

Conclusion/interpretation. The findings re-emphasise the need for good glycaemic control and assiduous treatment of hypertension if diabetic retinopathy is to be minimised. [Diabetologia (2001) 44: 156-163]

Keywords Type II (non-insulin-dependent) diabetes mellitus, retinopathy, randomised clinical trial, risk factors, incidence, progression, smoking, hypertension, glycaemia, $\mathrm{HbA}_{1 \mathrm{c}}$.
Received: 13 June 2000 and in revised form: 15 September 2000

Corresponding author: I.M. Stratton, Diabetes Trials Unit, Oxford Centre for Diabetes, Endocrinology and Metabolism, Radcliffe Infirmary, Woodstock Road, Oxford OX2 6HE, UK Abbreviations: UKPDS, UK Prospective Diabetes Study; DCCT, Diabetes Control and Complication Trial; MA, microaneurysm; LDL-C, low density lipoprotein cholesterol; HDL-C, high density lipoprotein cholesterol.

* Professor Turner died suddenly in August 1999 having worked on this paper.
Diabetic retinopathy is a common complication of Type II (non-insulin-dependent) diabetes mellitus and carries with it the threat of blindness. The St Vincent declaration [1] calls for intervention to lower both the incidence and prevalence of sight-threatening retinopathy. Thus, the identification and quantification of factors associated with onset and progression is essential if this is to be achieved. This paper reports the onset of new retinopathy and the progression of established retinopathy in the United Kingdom Prospective Diabetes Study (UKPDS [2]), a multicentre randomised controlled clinical trial of 
Table 1. Grading system

\begin{tabular}{|c|c|c|}
\hline Level & Severity & Definition \\
\hline 10 & DR absent & $\begin{array}{l}\text { All diabetic retinopathy features } \\
\text { absent }\end{array}$ \\
\hline 20 & MA only & $\begin{array}{l}\text { Microaneurysm(s) only, other le- } \\
\text { sions absent }\end{array}$ \\
\hline 35 & Mild NPDR & $\begin{array}{l}\text { MA plus retinal haemorrhage(s) } \\
\text { and/or hard exudates and/or cotton } \\
\text { wool spots }\end{array}$ \\
\hline 43 & $\begin{array}{l}\text { Moderate } \\
\text { NPDR }\end{array}$ & $\begin{array}{l}\text { Lesions as above }+ \text { either extensive } \\
\text { or severe HMA or IRMA present }\end{array}$ \\
\hline 47 & $\begin{array}{l}\text { Moderately } \\
\text { severe NPDR }\end{array}$ & $\begin{array}{l}\text { Lesions of } 35+\text { either extensive or } \\
\text { severe HMA with IRMA, or venous } \\
\text { beading }\end{array}$ \\
\hline 53 & Severe NPDR & $\begin{array}{l}\text { Extensive and severe HMA, } \\
\text { IRMA, and/or venous beading }\end{array}$ \\
\hline $\begin{array}{l}61,65,71 \\
75,81\end{array}$ & $\begin{array}{l}\text { Proliferative } \\
\text { DR }\end{array}$ & $\begin{array}{l}\text { NVD and/or NVE without or with } \\
\text { complications }\end{array}$ \\
\hline
\end{tabular}

where $\mathrm{DR}=$ diabetic retinopathy, NPDR = non-proliferative diabetic retinopathy, $\mathrm{MA}=$ microaneurysm, $\mathrm{HMA}=$ haemorrhages and microaneurysms, $\mathrm{HE}=$ hard exudates, $\mathrm{CWS}=$ cotton wool spots, IRMA = intraretinal microvascular abnormalities, NVD = new vessels on the disc, $\mathrm{NVE}=$ new vessels elsewhere

different treatments in newly diagnosed Type II diabetic patients. The incidence of microvascular disease (mainly retinopathy) has been reported previously together with its relation both to hypertension and glycaemic control [3-6]. The study showed that an intensive policy of glucose control reduced the risk of a two-step change in retinopathy grade at 12 years by $21 \%$ and that tight blood pressure control reduced the risk by $34 \%$. Other studies of retinopathy have addressed progression and incidence of retinal changes in Type I (insulin-dependent) diabetes mellitus (DCCT [7]) and mixed groups of Type I and Type II diabetes split by insulin usage [8].

This paper examines the relative importance of different risk factors (measured after 3 months of diet therapy) on the development and progression of diabetic retinopathy over 6 years in those patients with bilateral fundal photographs available at diagnosis and 6 years.

\section{Subjects and methods}

Details of the UKPDS patient recruitment and randomisation have been reported [2]. In brief, newly diagnosed Type II diabetic patients were treated for 3 months with diet alone [9]. If they remained hyperglycaemic (fasting plasma glucose $>6 \mathrm{mmol} / \mathrm{l}$ ) but symptom-free, they were allocated at random either to remain on a conventional glucose-control policy primarily with diet alone or to an intensive glucose-control policy with an oral hypoglycaemic agent or insulin. Patients were seen at 3-monthly intervals in a hospital clinic, with a more detailed medical examination at entry and every 3 years, including visual acuity determination, ophthalmoscopy and retinal photographs. Four standard stereo-pairs of retinal photographs of each eye were taken and assessed as described previously [10-11]. Although the study commenced in 1977, retinal photography did not start until 1983.

Clinical and biochemical methodology. Clinical histories were taken at the entry to the study, including smoking status categorised as non-smoker, ex-smoker or current smoker. The medical examination carried out included measurement of height and weight. Body mass index (BMI) was calculated as $\mathrm{kg} \cdot \mathrm{m}^{-2}$.

Data in this paper are presented using laboratory methods described previously [12]. Fasting plasma glucose measurements in each centre were monitored by the UKPDS glucose quality assurance scheme, with an inter-laboratory coefficient of variation (CV) of approximately $4 \%$ [13]. All other samples were measured by the central laboratory using assays monitored by tri-level quality control sera with Westgard rules [14] for acceptance as well as by external quality control schemes where possible. Biochemical methods were upgraded during the study and data realigned to new methods after relevant laboratory comparisons [12]. Measurement of $\mathrm{HbA}_{1 \mathrm{c}}$ by High Performance Liquid Chromatography (HPLC) on Biorad Diamat Automated Glycated Haemoglobin Analyser UK supplier (Bio-Rad Laboratories, Herts. UK) was certified by National Glycohaemoglobin Standardisation Program similar to the Diabetes Control and Complication Trial (DCCT).

Assessment of retinal photographs. Retinal photographs, masked for all patient-identifying details and assigned a unique identification number, were assessed initially by two independent, experienced readers for quality and adherence to protocol as well as the presence of any diabetic retinal lesions. Those thought to have lesions were then graded by two further readers in comparison with ETDRS final scale standard photographs [15] for severity of retinopathy. A computer algorithm subsequently assigned a modified ETDRS scale value to each eye. An abridged version of the scale is shown in Table $1 . \mathrm{Pa}-$ tient results were categorised using the worse eye / better eye system [16]. Thus 10/10 indicates absence of any retinopathy in both eyes, 20/10 microaneurysms (MA) in one eye only, and $20 / 20$ both eyes having MA only. Similarly, $35<35$ indicates the worse eye has some retinal haemorrhages or hard exudates or both or retinal haemorrhages and cotton wool spots or both in addition to microaneurysm, with the better eye having less retinopathy.

Ophthalmic endpoints. Episodes of photocoagulation or vitreous haemorrhage were confirmed by two independent clinical assessors who examined copies of admission notes and operation records. Any unresolved disagreements between the two assessors were referred to two further independent assessors for arbitration.

A clinically significant change in the level of retinopathy was protocol-defined as a two-step increment or decrement in the ETDRS scale between entry to UKPDS and 6-year photographs or the occurrence of photocoagulation or vitreous haemorrhage [3]. A two-step change would, for example, include a change from no retinopathy to microaneurysms in both eyes (incidence) or from microaneurysms alone in one eye only to cotton wool spots in one eye only (progression).

Statistical methods. Continuous variables were divided into thirds. Categorical variables were used where appropriate. Stepwise multiple logistic regression analysis was used to examine potential risk factors for the incidence and progression of diabetic retinopathy. Data were analysed using BMDP soft- 
Table 2. Characteristics of 1919 patients with complete data

\begin{tabular}{|c|c|c|c|}
\hline & No retinopathy at entry & $\begin{array}{l}\text { Retinopathy at entry } \\
\text { (at least } 2010 \text { ) }\end{array}$ & $\begin{array}{l}P \text { value for } \\
\text { difference }\end{array}$ \\
\hline$n$ & 1216 & 703 & \\
\hline $\operatorname{Sex}(\mathrm{M} / \mathrm{F}) n(\%)$ & $693 / 523(57.0 / 43.0)$ & $432 / 271(61.4 / 38.6)$ & 0.056 \\
\hline Age (years) & $52.2(8.5)$ & $52.2(8.6)$ & 0.96 \\
\hline Smoking status (non/ex/current) & $412 / 432 / 372(33.9 / 35.5 / 30.6)$ & $256 / 246 / 201(36.4 / 35.0 / 28.6)$ & 0.48 \\
\hline Body mass index $\left(\mathrm{kg} \mathrm{m}^{-2}\right)$ & $27.7(5.2)$ & $27.4(4.9)$ & 0.20 \\
\hline Fasting plasma insulin $(\mathrm{pmol} / \mathrm{l})^{\mathrm{b}}$ & $91(52$ to 160$)$ & 87 (50 to 152$)$ & 0.14 \\
\hline Cholesterol $\left(\mathrm{mmol} \mathrm{l}^{-1}\right)$ & $5.3(1.1)$ & $5.4(1.1)$ & 0.28 \\
\hline $\operatorname{LDL}\left(\mathrm{mmol} \mathrm{l}^{-1}\right)$ & $3.5(1.0)$ & $3.5(1.1)$ & 0.088 \\
\hline $\operatorname{HDL}\left(\mathrm{mmol} \mathrm{l}^{-1}\right)$ & $1.07(0.25)$ & $1.08(0.23)$ & 0.60 \\
\hline Triglyceride $\left(\mathrm{mmol} \mathrm{l}^{-1}\right)^{\mathrm{b}}$ & $1.5(0.9$ to 4.9$)$ & $1.5(0.9$ to 2.4$)$ & 0.49 \\
\hline Systolic blood pressure $(\mathrm{mm} \mathrm{Hg})$ & $134(18)$ & $137(20)$ & 0.0002 \\
\hline
\end{tabular}

${ }^{a}$ median and i.q. range

${ }^{\mathrm{b}}$ geometric mean and $1 \mathrm{~s}$.d. range

ware suite [17] and SAS software suite [18]. The data have been presented as floating relative risks which allow confidence intervals to be assigned to the comparator group. We consider a $p$ value of less than 0.01 as significant.

The variables included in the analysis, chosen if identified previously as risk factors in the literature [8], or on the basis of clinical relevance, were: $\mathrm{HbA}_{1 \mathrm{c}}$, systolic blood pressure, smoking status, LDL-C, HDL-C, body mass index sex, age, and ethnicity. Beta-cell function assessed by Homeostatic Model Assessment (HOMA) [19], was found to be strongly inversely related to progression but was not included since it is highly correlated with $\mathrm{HbA}_{1 \mathrm{c}}$ and could be a confounder. Similarly, fasting plasma glucose was regarded as being too closely linked to $\mathrm{HbA}_{1 \mathrm{c}}$ for inclusion, and diastolic blood pressure was not included as it is highly correlated with systolic blood pressure. In order to assess the degree to which baseline $\mathrm{HbA}_{1 \mathrm{c}}$ and blood pressure measurements may be counfounded by direct intervention on these two variables in the UKPDS subsidiary analyses of these two risk factors using updated mean $\mathrm{HbA}_{1 \mathrm{c}}$ and updated mean systolic blood pressure values were performed.

Because the number of subjects with photographs at entry and 9 years was one third smaller, 6-year data was analysed. A variable was included to differentiate between those with baseline retinopathy or none, and interaction between this and the independent variables for inclusion in the model was used as a marker to examine whether any of the variables had a different effect on incidence (no retinopathy to microaneurysms in both eyes or worse) from that on progression (established retinopathy progressing by two steps or more).

In the figures the significance reported for continuous data is the result obtained for fitting this as a continuous independent variable.

\section{Results}

There were 5102 patients recruited to UKPDS. Of these 1919 had high quality retinal photographs of both eyes at entry and 6 years later, and also had complete data set for the risk factors under consideration.
The baseline characteristics of these patients are shown in Table 2; of these 467 had retinopathy which progressed by two steps or more (Table 3 ). Those in the UKPDS who were not included in this analysis were generally similar to those who were included. More of those who were included were white $(86 \%$ vs $79 \%$ ) and older (median 50 vs 47 at diagnosis) and had lower $\mathrm{HbA}_{1 \mathrm{c}}(7.1 \%$ vs $7.3 \%)$. None of these factors was of a magnitude likely to affect the generality of the results. The patients who entered this analysis had a statistically significant ( $p=0.032)$ but clinically marginally lower mean diastolic blood pressure than those who were omitted ( $82 \mathrm{mmHg}$ vs $83 \mathrm{mmHg}$ ).

Incidence of new retinopathy and progression of established retinopathy. At total of 1919 patients were included in this analysis. Of these, 1216 had no retinopathy at diagnosis, and of those, 494 (41\%) subsequently developed at least one microaneurysm by 6 years (Table 3 ) and 264 (22\%) subsequently developed microaneurysms in both eyes or worse (incidence). Of the 703 patients with any retinopathy at entry, $203(29 \%)$ progressed by two steps or more over 6 years (progression).

The data were analysed to establish whether there was coherence between the incidence of new retinopathy and the deterioration of lesions detected at diagnosis. The analysis thus examined primary onset (or incidence) and secondary progression. The data were significantly disparate for incidence and progression $(p=0.00042)$ and for this reason interaction terms were included in the list available for the stepwise logistic regression model.

Incidence and progression and associated risk factors: $H b A_{1 c}$. There was a highly significant positive asso- 
Table 3. Two-way table of retinopathy at diagnosis by retinopathy after 6 years

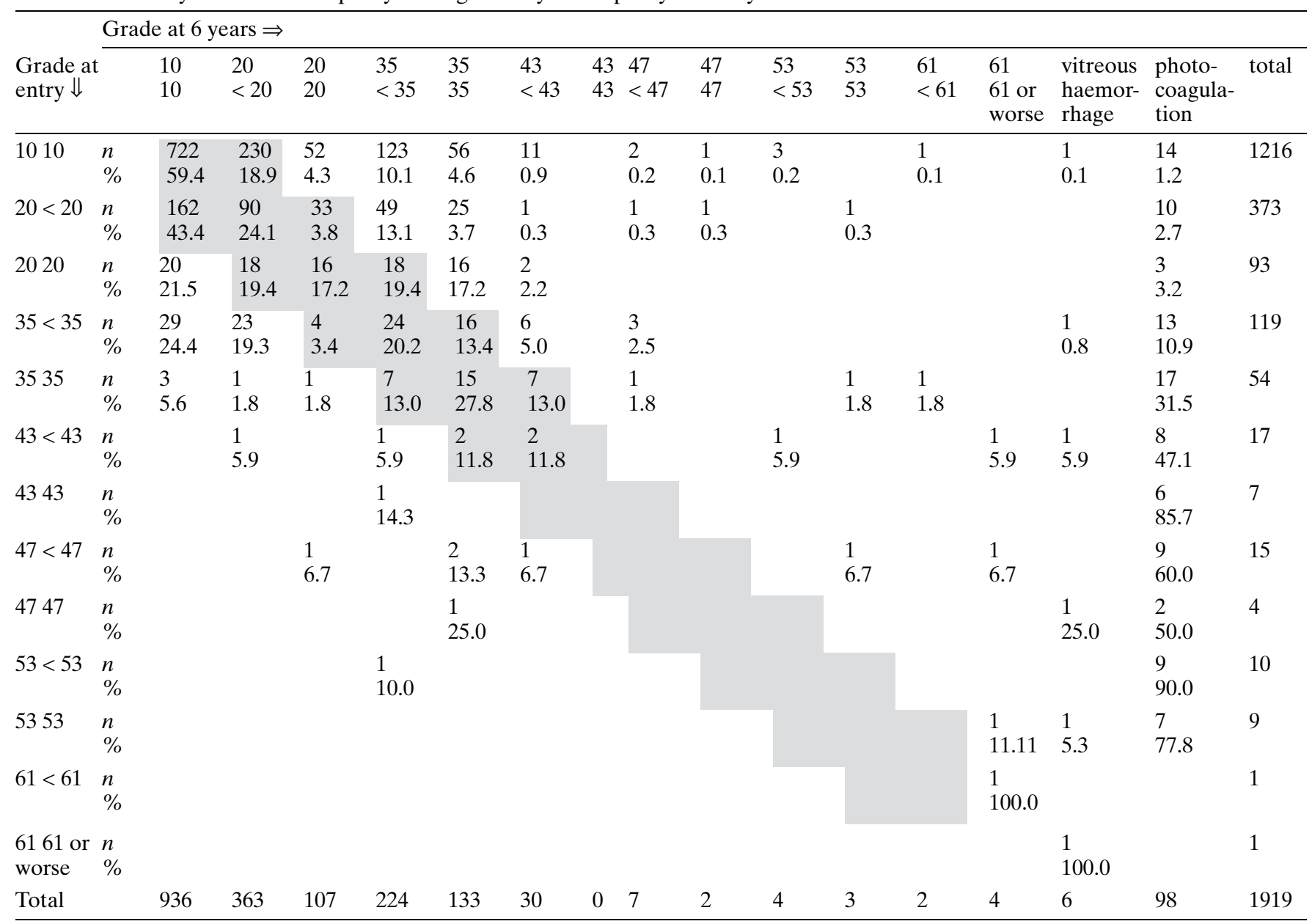

Table 4. Univariate logistic regression results

\begin{tabular}{llll}
\hline & $p$ value for 2 steps & $\begin{array}{c}p \text { value for 2 steps } \\
\text { from no retinopathy }\end{array}$ & $\begin{array}{c}p \text { value for 2 steps } \\
\text { from any retinopathy }\end{array}$ \\
\hline Systolic blood pressure & $<0.0001$ & $<0.0001$ & 0.020 \\
HbA $_{1 \mathrm{c}}$ & $<0.0001$ & $<0.0001$ & $<0.0001$ \\
Smoking status & 0.0101 & 0.0068 & 0.040 \\
LDL cholesterol & 0.8274 & 0.67 & 0.018 \\
HDL cholesterol & 0.0883 & 0.21 & 0.78 \\
Triglyceride & 0.8186 & 0.80 & 0.14 \\
Body mass index & 0.9591 & 0.24 & 0.13 \\
Sex & 0.9318 & 0.17 & 0.21 \\
Age & 0.0125 & 0.19 & 0.0051 \\
Race & 0.0063 & 0.057 & 0.14 \\
Insulin & 0.0582 & 0.33 & 0.47 \\
\hline
\end{tabular}

ciation of incidence and progression with $\mathrm{HbA}_{1 \mathrm{c}}$ in the univariate analyses (Table 4). In the multivariate logistic regression model (Fig.1) $\mathrm{HbA}_{1 \mathrm{c}}$ was strongly associated with incidence and progression and the gradient was steeper for progression. The relative risk in the middle third $\left(\mathrm{HbA}_{1 \mathrm{c}} 6.2\right.$ to $7.4 \%$ ) for those with no retinopathy was 1.4 (CI 1.1 to 1.8 ) and 2.5 (CI 2.0 to 3.2) in the top third. In those with retinopathy at diagnosis the relative risk was 4.1 (CI 3.1 to 5.6) in the middle third and 8.1 (CI 6.3 to 10.5) in the top third $\left(\mathrm{HbA}_{1 \mathrm{c}} \geq\right.$ $7.5 \%)$.

The subsidiary analysis using updated mean $\mathrm{HbA}_{1 \mathrm{c}}$ showed a similar association with a gradient across the tertiles from $18 \%$ incidence in the lowest third to $32 \%$ in the top third ( $p<0.0001$ for trend) and for progression $18 \%$ in the bottom third to $40 \%$ in the top third ( $\mathrm{p}<0.0001$ for trend). 

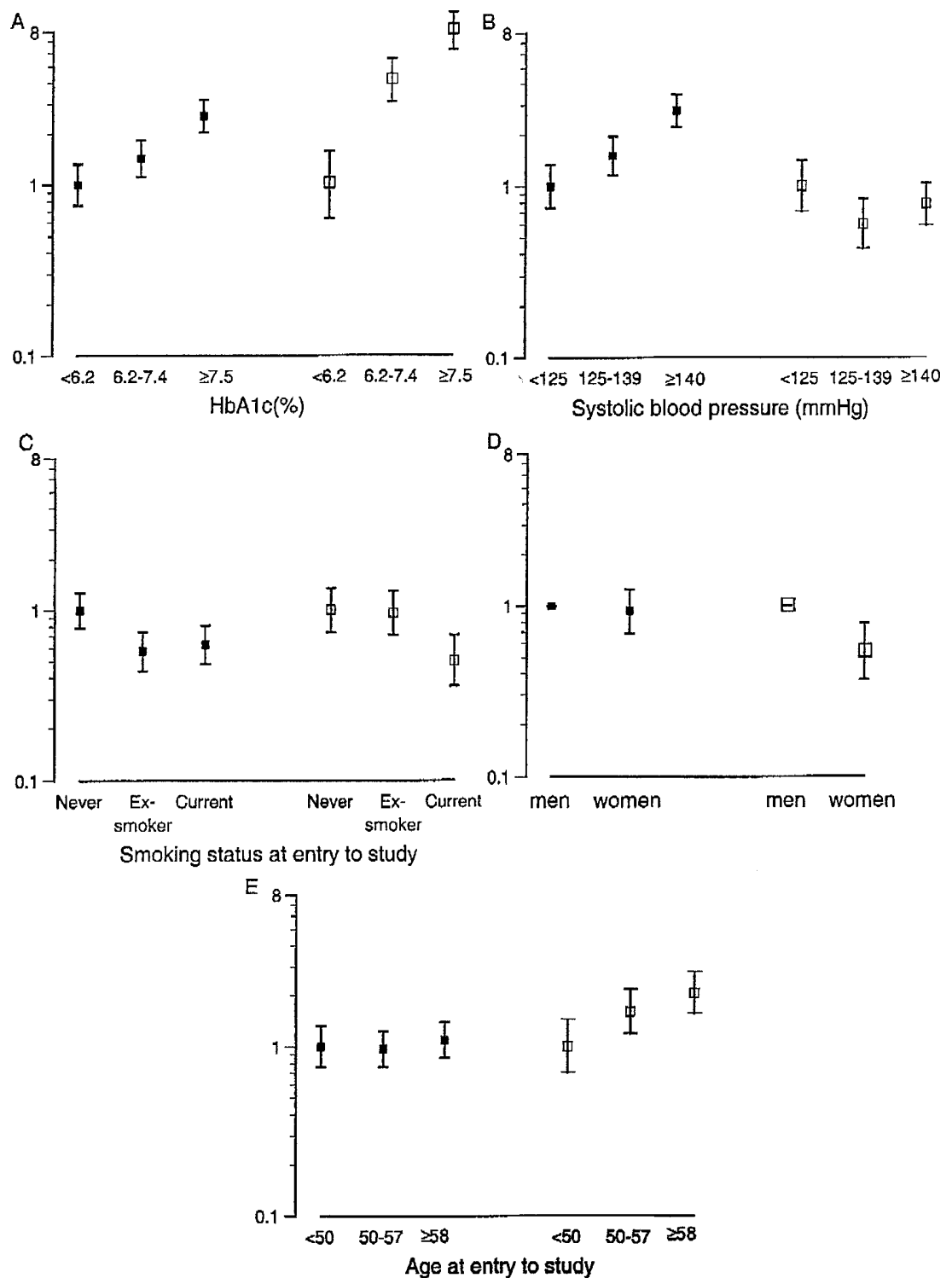

Fig. 1 A-E Floating relative risks for incidence of new retinopathy ( $\square$ ) and progression of retinopathy, defined as two steps or more on the modified ETDRS final scale $(\square)$. Point estimates and $95 \%$ confidence intervals are shown. (A) $\mathrm{HbA}_{1 \mathrm{c}}$ : incidence $p<0.0001$; progression $p<0.0001 ; p=0.076$ for difference between incidence and progression. (B) systolic blood pressure: incidence $p<0.0001$; progression $p=0.92 ; p=$ 0.0001 for difference between incidence and progression. $(\mathbf{C})$ smoking status: incidence $p=0.0043$; progression $p=0.0045$; $p=0.0010$ for difference between incidence and progression. (D) sex: incidence $p=0.67$; progression $p=0.0016$; $p=0.038$ for difference between incidence and progression. (E) age: incidence $p=0.99$; progression $p<0.0012 ; p=0.084$ for difference between incidence and progression

Systolic blood pressure. Systolic blood pressure was significantly associated with retinopathy incidence $(p<0.0001)$, with those in the middle third $(125-139 \mathrm{mmHg}$ ) having a relative risk of 1.5 (CI 1.2 to 2.6 ) and the top third ( $\geq 140 \mathrm{mmHg}$ ) 2.8 (CI 2.2 to 3.5) (Fig.1). There was no relation of retinopathy progression with systolic blood pressure.

The subsidiary analysis using updated mean blood pressure showed a gradient across the tertiles from $17 \%$ incidence in the lowest third to $32 \%$ in the top third for incidence of new retinopathy $(p<0.0001$ for trend), and for progression a smaller effect from $26 \%$ in the bottom third to $36 \%$ in the top third $(p=0.005$ for trend).

Smoking. Smoking status was associated with reduced incidence of retinopathy with current smokers having a relative risk of 0.63 (CI 0.48-0.82). Similarly, for progression of retinopathy current smokers compared with those who had never smoked and had a relative risk of 0.50 (CI 0.36 to 0.71 ) (Fig. 1).

Age and sex. Incidence of retinopathy was the same in men and women (Fig.1), but in the multivariate model women had lower relative risk (RR) of pro- 
gression RR 0.54 (CI 0.37 to 0.80 ). There was no effect of age on incidence (Fig. 1), but a higher proportion of older subjects progressed, with those in the middle third (age 50-57 at entry) having a relative risk of 1.6 (CI 1.2 to 2.2) and those in the top third (58 or older at entry) having a relative risk of 2.1 (CI 1.5 to 2.7$)$.

\section{Discussion}

We report here the incidence and progression of retinopathy in a cohort of people with Type II diabetes followed from diagnosis. There have been no substantive reports to date on incidence and progression of retinopathy using prospective longitudinal data from newly diagnosed Type II diabetic subjects, although the DCCT study [7] reported data from Type I diabetes patients and the Wisconsin study reported on a mixed group of newly diagnosed and previously diagnosed patients on insulin [8].

The fact that $37 \%$ of UKPDS subjects had retinopathy at presentation [20] suggests that there had been considerable time between onset of the disease and its clinical presentation [21]. Since the UKPDS also showed that the need for photocoagulation was reduced by intensive blood glucose control $(p=$ $0.003)$ and tight blood pressure control $(p=0.03)$ [3-6], guidelines now emphasise the necessity for early and adequate therapeutic intervention.

Many epidemiological studies suggest that glycaemic control plays an important part in the development of microvascular complications [22]. The DCCT study of improved glycaemic control in Type I diabetes patients shows an unequivocal effect of glycaemia as measured by $\mathrm{HbA}_{1 \mathrm{c}}$ [23]. We show here a similar relation (in Type II diabetes patients) of progression of retinopathy by tertile of baseline $\mathrm{HbA}_{1 \mathrm{c}}$, with an eightfold relative risk over the group with median $\mathrm{HbA}_{1 \mathrm{c}}$ of $6.2 \%$ or less for the group with $\mathrm{HbA}_{1 \mathrm{c}}$ of more than or equal to $7.5 \%$ and a 2.5 -fold relative risk of incidence between the same groups. An analysis using updated $\mathrm{HbA}_{1 \mathrm{c}}$ was undertaken, which confirmed the steep association between $\mathrm{HbA}_{1 \mathrm{c}}$ exposure and both incidence and progression of diabetic retinopathy. The UKPDS demonstrated that improvement in glycaemic control improved microvascular disease and retinopathy outcomes. In the trial a difference of $\mathrm{HbA}_{1 \mathrm{c}}$ between a median of $7.9 \%$ in conventional therapy group and $7 \%$ in intensive therapy group over the first ten years resulted in a risk reduction for progression of retinopathy at 12 years of $21 \%$ assessed as a twostep change [3-6]. Thus both baseline and updated mean data are concordant with regard to escalated risk with higher $\mathrm{HbA}_{1 \mathrm{c}}$ and the therapeutic trial demonstrated that intensive therapy improved outcomes.
In common with previous studies of Type II diabetes [24-26], higher blood pressure was strongly associated with onset of retinopathy. The upper third ( $\geq 140 \mathrm{mmHg}$ ) includes all those who were hypertensive on current criteria [27] but even those with systolic blood pressure 125 to $139 \mathrm{mmHg}$ at diagnosis had significantly higher incidence than the lowest third (systolic $<125 \mathrm{mmHg}$ ). The updated mean systolic blood pressure showed a similar strong association for incidence and a less steep effect for progression. These data are in accord with previous studies in Japanese patients with Type II diabetes [24] and with a large (1005 patient) epidemiological study in South Africa [25] and a mixed population of Type I and Type II patients reported by Segato [26] in Italy $(n=1321)$. The UKPDS reported a pronounced decrease in microvascular end points with tight blood pressure control [3-6] and suggested that tight control of hypertension was needed in Type II diabetes patients. Many have previously regarded systolic blood pressure of less than $140 \mathrm{mmHg}$ acceptable in Type II diabetes patients, the majority of whom are over 50 years old, but these data, together with the trial results, suggest that this is inadequate to prevent the onset of retinopathy.

Somewhat counter-intuitively, smoking status was inversely related to the development of new lesions and to the progression of established retinopathy. This finding is not likely to be chance alone because of the strength of the association. It, however, is at variance with much of the published epidemiology of diabetic retinopathy. The differences in findings could be related to the small size of many studies where no association was found [28-31] but where a Type II statistical error is possible. For example no association in 129 Type II patients has been reported [28], and no differences in 163 patients reviewed have been found [29], but the size of the effect we describe here would not be seen in studies of this size. Larger mixed epidemiological studies [26], where 1321 patients with either Type I or Type II diabetes were examined [32,33], also showed no significant relation with smoking. Such studies have consistently found hyperglycaemia associated with retinopathy and this could be related to smoking in epidemiological studies or might simply be a marker of those who adopt a casual attitude to health care. Within the UKPDS this possibly confounding effect would have been removed by randomisation. Fewer current smokers attended all scheduled follow-up visits than those who were not current smokers $(55 \% v s .60 \%$ respectively, $p=0.0004$ ), suggesting that the current smokers might not have been as assiduous in their uptake of medical care as non-smokers. Another possible explanation is that of publication bias. Physicians could have been reluctant to report similar findings [34]. Some other studies support our findings: a report of an increased relative risk in smokers in South 
Wisconsin of 1.06 (95 \% CI 0.97-1.18) for the development of retinopathy in younger $[<30$ years old) patients, but the reverse in older patients (presumably predominantly Type II) with a risk of 0.89 (95\% CI 0.75-1.06) [34].

There could be quite specific reasons for the effect of smoking that we describe here; perhaps the association of smoking with lower blood pressure [36] might have accounted for the univariate reduction. The presence of the effect in the multivariate model suggests that there could be an independent effect, perhaps the pharmacological effect of nicotine itself or of one of the many other active compounds found in tobacco smoke [37]. This finding does not, however, justify advising patients with diabetes to smoke because the deleterious effects of tobacco consumption in terms of cardiovascular and lung cancer risk would far outweigh the retinopathy risk reduction in terms of total morbidity. Smoking has also been independently associated with progression of nephropathy in Type II diabetes patients [38].

In conclusion, these data from the UKPDS show that retinopathy onset (incidence) was strongly associated with baseline glycaemia and glycaemic exposure over 6 years, with higher blood pressure and inversely with smoking. In those who already had retinopathy, progression was associated with not smoking, older age, male sex and glycaemia as evidenced by a higher $\mathrm{HbA}_{1 \mathrm{c}}$. The findings re-emphasise the need for intensive glycaemic control and assiduous treatment of hypertension if diabetic retinopathy is to be controlled and reduced.

Acknowledgements. We would like to thank the following participating centres for their help: Royal Infirmary, Aberdeen; City Hospital, Belfast; Royal Victoria Hospital, Belfast; General Hospital, Birmingham; St.Helier Hospital, Carshalton; Derbyshire Royal Hospital, Derby; Ninewells Hospital, Dundee; Royal Devon and Exeter Hospital, Exeter; Ipswich Hospital, Ipswich; Leicester General Hospital, Leicester; St. George's Hospital, London; Hammersmith Hospital, London; Whittington Hospital, London; Royal Infirmary, Manchester; Norfolk and Norwich Hospital, Norwich; Northampton General Hospital, Northampton; Radcliffe Infirmary, Oxford; Peterborough Hospital, Peterborough; Hope Hospital, Salford; Lister Hospital, Stevenage; North Staffordshire Royal Infirmary, Stoke-on-Trent; Torbay Hospital, Torbay. The authors are indebted to the participating patients. This work was supported by grants from: The National Eye Institute 2 UO1 EY07049-09, Bethesda, Maryland; British Diabetic Association; Medical Research Council; National Institutes of Digestive Disorders and Kidney Disease NIH, Bethesda, Maryland; UK Department of Health; British Heart Foundation and from pharmaceutical companies including: Bayer, Bristol Myers Squibb, Hoechst, Lilly, Novo-Nordisk, Lipha and Farmitalia Carlo Erba and from additional companies including Securicor, Kodak and Cortecs Diagnostics. Other funding companies and agencies, the supervising committees, and all participating staff listed in an earlier paper [3]. We thank Carol Hill for assistance with the preparation of this paper.

\section{References}

1. Declaration TSV (1990) Diabetes Care and Research in Europe. Diabet Med 7: 360

2. UKPDS Group (1991) UK Prospective Diabetes Study VIII: Study design, progress and performance. Diabetologia 34: 877-890

3. UKPDS Group (1998) Intensive blood-glucose control with sulphonylureas or insulin compared with conventional treatment and risk of complciations in patients with Type II diabetes (UKPDS 33). Lancet 352: 837-854

4. UKPDS Group (1998) Tight blood pressure control and risk of macrovascular and microvascular complications in Type II diabetes: UKPDS 38. BMJ 317: 703-713

5. UKPDS Group (1998) Efficacy of atenolol and captopril in reducing risk of macrovascular and microvascular complications in Type II diabetes: UKPDS 39. BMJ 317: 713-726

6. UKPDS Group (1998) Effect of intensive blood-glucose control with metformin on complications in overweight patients with Type II diabetes (UKPDS 34). Lancet 352: 854-865

7. DCCT Research Group (1993) The effect of intensive diabetes treatment on the development and progression of long term complication in insulin-dependent diabetes mellitus. N Eng J Med 329: 977-986

8. Klein R, Klein B, Moss S, Cruickshanks K (1994) The Wisconsin Epidemiologic Study of Diabetic Retinopathy XIV. Ten year incidence and progression of diabetic retinopathy. Arch Ophthalmol 112: 1217-1228

9. UKPDS Group (2000) Effects of 3 months' diet after diagnosis of Type II diabetes on plasma lipids and lipoproteins (UKPDS 45). Diabetologia 43: (in press)

10. UKPDS Group (1997) UK Prospective Diabetes Study 30: Diabetic retinopathy at diagnosis of Type II diabetes and associated risk factors. Arch Ophthalmol 116: 297-303

11. UKPDS Group (1999) Microaneurysms in the development of diabetic retinopathy (UKPDS 40). Diabetologia 42: 1107-1112

12. UKPDS Group (1994) UK Prospective Diabetes Study XI: Biochemical risk factors in Type II diabetic patients at diagnosis compared with age-matched normal subjects. Diabet Med 11: 534-544

13. UKPDS Group (1983) UK Prospective Diabetes Study I: Effect of diet, sulphonylurea, insulin or biguanide therapy on fasting plasma glucose and body weight over one year. Diabetologia 24: 404-411

14. Westgard JO, Barry PL, Hunt MR, Groth T (1981) A multi-rule Shewhart chart for quality control in clinical chemistry. Clin Chem 27: 493-501

15. Early Treatment Diabetic Retinopathy Study Group (1985) Chapters 12 and 18. Early Treatment Diabetic Retinopathy Study Group: Manual of Operations. U.S. Department of Commerce. National Technical Information Service, 5285 Port Royal Road, Springfield, VA 22161, Accession \# PB85223006/AS., Baltimore, Dept. of Epidemiology and Preventative Medicine, University of Maryland School of Medicine

16. Klein R, Klein B, Moss S, Davis M, DeMets D (1984) The Wisconsin Epidemiologic Study of Diabetic Retinopathy: II. Prevalence and risk of diabetic retinopathy when age at diagnosis is less than 30 years. Arch Ophthalmol 102: 520-526

17. BMDP (1990) BMDP Statistical Software Manual, BMDP Statistical Software, Los Angeles, California, USA

18. SAS (1989) SAS/STAT Users Guide 1st Edition. NC. SAS Institute Inc. Cary, North Carolina, USA 1: 851-859, 2: 1071-1126 
19. Matthews DR, Hosker JP, Rudenski AS, Naylor BA, Treacher DF, Turner RC (1985) Homeostasis model assessment: insulin resistance and beta-cell function from fasting plasma glucose and insulin concentrations in man. Diabetologia 28: 412-419

20. UKPDS Group (1998) Diabetic retinopathy at diagnosis of Type II diabetes and associated risk factors. Arch Ophthalmol 116: 297-303

21. Harris M, Klein R, Welborn T et al. (1992) Onset of NIDDM occurs at least 4-7 years before clinical diagnosis. Diabetes Care 15: 815-819

22. Pirart J (1977) [Diabetes mellitus and its degenerative complications: a prospective study of 4,400 patients observed between 1947 and 1973 (2nd part) (author's transl)]. Diabetes Metab 3: 173-82

23. The Diabetes Control and Complications Trial Research Group (1993): The effect of intensive treatment of diabetes on the development and progression of long-term complications in insulin-dependent diabetes mellitus. N Engl J Med 329: 977-986

24. Fujisawa T, Ikegami H, Yamato E et al. (1999) Association of plasma fibrinogen level and blood pressure with diabetic retinopathy, and renal complications associated with proliferative diabetic retinopathy in Type II diabetes mellitus. Diabet Med 16: 522-526

25. Mouton D, Gill A (1988) Prevalence of diabetic retinopathy and evaluation of risk factors. A review of 1,005 diabetic clinic patients. S Afr Med J 15: 399-402

26. Segato T, Midena E, Grigoletto F et al. (1991) The epidemiology and prevalence of diabetic retinopathy in the Veneto region of north east Italy. Veneto Group for Diabetic Retinopathy. Diabet Med 8: S11-S16

27. Group EDP (1999) A desktop guide to Type II Diabetes Mellitus. Diabet Med 16: 716-730
28. Owens D, Volund A, Jones D et al. (1988) Retinopathy in newly presenting non-insulin-dependent (Type II) diabetic patients. Diabetes Res 9: 59-65

29. Madsbad S, McNair P, Christensen M et al. (1980) Influence of smoking on insulin requirement and metabolic status in diabetes mellitus. Diabetes Care 3: 41-43

30. Guillausseau P, Massin P, Charles M et al. (1998) Glycaemic control and development of retinopathy in Type II diabetes mellitus: a longitudinal study. Diabet Med 15: 151-155

31. Rasmidatta S, Khunsuk-Mengrai K, Warunyuwong C (1998) Risk factors of diabetic retinopathy in non-insulin dependent diabetes mellitus. J Med Assoc Thai 81: 169-174

32. Moss S, Klein R, Klein B (1996) Cigarette smoking and ten year progression of diabetic retinopathy. Ophthalmology 103: $1438-1442$

33. Moss S, Klein R, Klein B (1991) Association of cigarette smoking with diabetic retinopathy. Diabetes Care 14: 119-126

34. Easterbrook P, Berlin J, Gopalan R, Matthews D (1991) Publication Bias in Clinical Research. Lancet 337: 867-872

35. Klein R, Klein B, Davis M (1983) Is cigarette smoking associated with diabetic retinopathy? Am J Epidemiol 118: 228-238

36. HDSG II HiDSG (1993) Increased risk of cardiovascular complications in hypertenstive Type II diabetic patients. Journal of Hypertension 11: 319-325

37. Solberg Y, Rosner M, Belkin M (1998) The association between cigarette smoking and ocular diseases. Surv Ophthalmol May-Jun 42(6): 535-47

38. Biesenbach G, Grafinger P, Janko O, Zazgornik J (1997) Influence of cigarette smoking on the progression of clinical diabetic nephropathy in Type II diabetic patients. Clin Nephrol Sep. 48(3): 146-50 